\title{
Collaborative Game Design with Children with Hemophilia as a Tool for Influencing Opinions about Physical Activity at School
}

\author{
Jérôme Dinet ${ }^{\mathrm{a}^{*}}$, Capucine Bauchet ${ }^{\mathrm{a}, \mathrm{b}}$, Lara Hoareau $^{\mathrm{a}}$ \\ ${ }^{a}$ University of Lorraine, Nancy, France \\ ${ }^{b}$ Rectorat de l'Académie de Nancy-Metz, Nancy, France \\ ${ }^{\star}$ Corresponding author. E-mail: jerome.dinet@univ-lorraine.fr
}

Background. More than 295,000 people have been identified with bleeding disorders worldwide, the majority being hemophiliacs $(184,560$; data from the World Federation of Hemophilia, 2017). Hemophilia poses a paradox: Physical activity is recommended for children with hemophilia for the sake of their health and to promote inclusion, but teachers are reluctant to involve them in sports at school. School psychologists play a key role in helping patients and their families adapt and learn to cope with their new reality, and they provide psychosocial support by helping patients and their families develop strategies to cope with physical, mental, emotional, and social challenges related to hemophilia.

Objective. The objective of this study is to include children with hemophilia, and their parents and teachers, in a participatory process to design an innovative digital tool for modifying mental representations of parents and teachers about the importance of physical activity and sports at school for hemophiliacs.

Design. The present study is based on a pre-/post-test design where the mental representation about hemophilia of all individuals concerned (16 children with hemophilia: mean age $=7.8$ years, $S D=1.9$; their parents; and their teachers) is collected twice: at the beginning (pre-test) and at the end (post-test) of the process of collaborative game design.

Results. Even though fathers, mothers, and teachers perceive some sports as more risky than others (e.g., rugby, soccer, cycling), they modified their opinions positively about the necessity of physical activity and sports at school for children with hemophilia. The results showed that the collaborative design of this prototype of an innovative educational tool positively influenced the opinions of fathers, mothers, and teachers about the role of physical activity and sports at school, for their children with hemophilia.

Conclusion. Although the choice of physical activity or sport must be individual and must be discussed with the psychologist, parents, teachers, and children, this hemophilia "team" must discuss the risks and benefits of different sports, taking account of the physical and psychological conditions, because for all these children, physical activity and exercise have many positive benefits for health and can help self-esteem, learning, and inclusion in schools.

Keywords: hemophilia, serious game, mental representation, collaborative design, focus group. 


\section{Introduction}

Hemophilia poses a paradox: Physical activity is recommended for children, but teachers are reluctant to involve children with hemophilia in sports at school. Because hemophilia (hemophilia A or B) can reduce blood clotting and cause excessive bleeding, and because many people with hemophilia also have joint problems related to chronic bleeding, teachers are afraid of involving children with hemophilia in physical activities and sports. But physical activity can help improve movement for these individuals (Dinet, 2015; Fromme et al., 2007; Gomis et al., 2009), build muscle strength, and maintain physical fitness (Von Mackensen, 2007), especially for young children (Van der Net, 2006). Not all sports are suitable for pupils living with hemophilia, such as those involving collision or physical contact (Heijnen, Mauser-Bunschoten, \& Roosendaal, 2000; Manco-Johnson, 2012), but athletic participation with appropriate supervision and precautions should be encouraged in children with hemophilia. This can act as a preventative measure, potentially offering health benefits in an increasingly overweight pediatric population (Ross, Goldenberg, Hund, \& Manco-Johnson, 2009). Furthermore, early socialization supported by social physical activity is important for children with chronic illnesses, who may encounter barriers to socialization later on (e.g., missed school, feeling different). Early social interactions help them develop self-confidence and a sense of belonging, and learn how to interact with others.

\section{Hemophilia at School}

If teachers in primary schools (and sometimes in secondary schools) are not always comfortable educating pupils with bleeding disorders or allowing them to participate in sports, their reluctance may be related to a lack of knowledge about hemophilia. Caution and injury prevention are important for people with hemophilia; however, it is important to distinguish between injury prevention and overprotection.

One of the main problems is that these children have difficulties describing their conditions, the activities they can or cannot practice, and the cause of their concerns. Physical or functional limitations can make young children with hemophilia feel shy and embarrassed or lead them to be teased by others. It should not be not necessary for children with hemophilia or their teachers to make a special point of telling the class about the disease every year, but it is important for children with hemophilia to be able to explain their bruises or health factors that may cause them to miss school occasionally. Therefore psychosocial support is an important part of comprehensive care for people with hemophilia. Beyond the medical condition, these individuals commonly face a number of psychosocial challenges.

While improving communication about hemophilia within families is important (Gregory et al., 2007), little attention has been paid to communication among young patients, families, and teachers. Yet several studies with school-aged children have identified a significant association between the number of bleeding episodes experienced by children with hemophilia and their academic achievement, in a cohort of school-aged children (Colegrove \& Huntzinger, 1994; Shapiro et al., 2001; Usner et al., 1998). One of the main reasons is that absenteeism is a significant factor in the academic and social situation of children with hemophilia. In addition data support the assertion that therapeutic care programs in this population must 
be evaluated, not only in terms of the financial cost, to achieve adequate musculoskeletal outcomes.

The psychological impact of pediatric chronic illness on peer relations and social adjustment in nine school-aged boys with hemophilia was examined by Williams \& Chapman (2009) using qualitative interview methods. Three main themes emerged from the interviews: awareness of difference, efforts to conceal difference, and efforts to connect with peers and friends. The findings suggest that hemophilia may be a socially stigmatizing condition for many boys, because it limits gendertypical interactions with same-sex peers.

Socialization is important for many children with chronic illnesses, who may encounter barriers to socialization (e.g., missing school, feeling different). Social interactions help them develop self-confidence and a sense of belonging, and learn how to interact with others. Parents and teachers should be encouraged to take advantage of early opportunities for socialization, such as playing with peers and participating in community events for children, and sports and physical activities at school. Physical exercise and sports constitute a basic premise in the treatment of hemophilia. A child with hemophilia would benefit from exercise and sports, both because good muscle tone can decrease the frequency of bleeds, joint problems, and loss of bone mineral density, and because it can contribute to improving their quality of life. In other words, physical activity should be encouraged, with attention paid to muscle strengthening, coordination, general fitness, physical functioning, healthy body weight, and self-esteem. The school staff and peers should be informed that a child has hemophilia, preferably by the parents, and education of school personnel regarding suitable activities for the child is recommended.

\section{From the Design to the Co-design of Serious Games for Patients}

Recent evolution in game design research from a user-centered approach to a collaborative designing is changing the roles of the designer, the researcher, and the end-user (Sanders \& Stappers, 2008), especially when end-users are patients (Sanders, 2006).

Over the past six decades, designers have been moving closer to the future users of what they design. The developments are well consolidated in industrial practice and education as the adoption of user-centered designs from an "expert perspective" in which trained researchers observe and/or interview largely passive users, whose contribution is to perform tasks as instructed and/or to give their opinions about product concepts that were generated by others. The user-centered design approach ("user as subject") has been primarily a US-driven phenomenon. Increasingly since the 1970s, people have been given more influence and room for initiative in roles where they provide expertise and participate in informing, imagining, and conceptualizing activities in the early design phases. The participatory approach ("user as partner") has been led by Northern Europeans.

Healthcare professionals often think they have expert knowledge that will improve care and create value for patients (Bates \& Roberts, 2006; Gustavsson \& Andersson, 2017). Nowadays, patients are becoming important resources in healthcare improvement by contributing with their personal experiences. The first examples of collaborative treatment with patients in healthcare came from a head and neck cancer clinic (Bate \& Robert, 2006, 2007; Pickles, Hide, \& Maher, 
2008). The method was subsequently used elsewhere, such as in emergency health services (Iedema et al., 2010), breast and lung cancer services (Boyd et al., 2012; Tsianakas et al., 2012), neonatal care (Gustavsson, 2014), outpatient services for the elderly (Bowen, Dearden, Wolstenholme, \& Cobb, 2011), and mental health (Larkin, Boden, \& Newton, 2015). The results of such collaborative design projects included fast access to reliable health advice, effective treatment delivered by trusted professionals, involvement in decisions, respect for preferences, clear and comprehensible information and support for self-care, attention to physical and environmental needs, and assurance that healthcare professionals draw upon the experiences of patients and their families in order to truly reflect patient needs and attitudes (Maher \& Baxter, 2009).

While collaborative treatment design has emerged as a useful concept where stakeholders and end-users have a greater stake in designing the end product, few accounts exist of the use of the concept in game design for children with chronic diseases, as Chomutare, Johansen, Hartvigsen, and Arsand (2016) have pointed out. Several papers have, however, described the different steps in collaborative game design for children with type 1 diabetes (Beltrand et al., 2017; Chomutare, Johansen, Hartvigsen, \& Arsand, 2016; Godot et al., 2016; Jurdi et al., 2018). In those instances a game does exist for hemophiliacs (e.g., Hemoquest, conceived by Matsunaga et al., 2014), it is intended for use in hospitals by staff who supervise their patients and its role is mainly to give information to children about their illness, the adults involved being the medical staff (i.e., experts).

\section{Main Goals}

The impact of digital tools, such as serious games, is generally assessed by analyzing their use, usability, and acceptability. The originality of our research is to concentrate on the impact of the process of collaborative design on opinions of relevant stakeholders, and not on the impact of the use itself.

The study presented here describes the development of an educational game that is aimed at children with hemophilia. The two main objectives of this game and the process of collaborative design are:

- to include children with hemophilia, their parents, and their teachers in a participatory collaborative design process for an innovative digital tool about hemophilia;

- to influence mental representations by parents and teachers about the importance of physical activity and sports at school for hemophiliacs.

\section{Method}

This present study is based on a pre-/post-test design, in the sense that mental representations of hemophilia for all individuals concerned (children, parents, and teachers) are collected twice: at the beginning (pre-test) and at the end (post-test) of the collaborative game design process. These two sessions (pre- and post-test) were four months apart (September 2018, January 2019). Between these two sessions, all the participants were asked to enroll in several focus groups for the collaborative design of a game dedicated to hemophilia at school. 


\section{Participants}

Sixteen French families with children with hemophilia (A and B; age range from 6 to 10 years; mean age $=7.8$ years, $S D=1.9$ ) were recruited to participate. The 16 teachers of these 16 children also participated in this study as volunteers.

Among the children with hemophilia, 12 children had mild hemophilia - factor VIII or IX level ${ }^{1}(=6-50 \%$, moderate hemophilia - factor VIII or IX level) and four children had severe hemophilia - factor VIII or IX level $(<1 \%)$. All the participants were distributed among four focus groups, with four participants in each group (one child, one father and one mother, and one teacher).

\section{Focus Group}

Focus group interviews were done each month for five months (from September 2018 to January 2019) with the 16 children with hemophilia, their parents (fathers and mothers), and their teachers. As Table 1 shows, some children and parents were sometimes absent for professional or medical reasons. But the engagement of all the participants was high throughout this study.

Table 1

Presence of the participants (number) during the five sessions dedicated to co-design of the serious game, for each of the four groups

\begin{tabular}{llccccc}
\hline \multirow{2}{*}{ Group 1 } & Sept 2018* & Oct 2018 & Nov 2018 & Dec 2018 & Jan 2019** \\
& Children & 4 & 4 & 3 & 4 & 4 \\
& Fathers & 2 & 4 & 3 & 3 & 4 \\
& Mothers & 4 & 4 & 3 & 4 & 4 \\
& Teachers & 4 & 4 & 4 & 3 & 4 \\
\hline \multirow{2}{*}{ Group 2 } & Children & 4 & 4 & 2 & 4 & 4 \\
& Fathers & 4 & 4 & 2 & 3 & 2 \\
& Mothers & 4 & 4 & 2 & 4 & 4 \\
\multirow{6}{*}{ Group 3 } & Teachers & 4 & 4 & 3 & 4 & 4 \\
& Children & 4 & 4 & 2 & 4 & 4 \\
& Fathers & 4 & 4 & 2 & 3 & 2 \\
& Mothers & 4 & 4 & 2 & 4 & 4 \\
& Teachers & 4 & 4 & 3 & 4 & 4 \\
\hline \multirow{6}{*}{ Group 4 } & Children & 4 & 4 & 2 & 4 & 4 \\
& Fathers & 2 & 2 & 2 & 2 & 4 \\
& Mothers & 3 & 4 & 2 & 4 & 3 \\
& Teachers & 4 & 4 & 3 & 3 & 4 \\
\hline
\end{tabular}

Note: ${ }^{\star}$ pre-test session; ${ }^{* *}$ post-test session

1 In hemophilia, a blood clotting factor is missing. In hemophilia A, factor VIII is missing, while in hemophilia B, factor IX is missing. Without these factors, blood will not clot well, and the individual may bleed easily or may not stop bleeding once it has started. 
Research using focus groups began in the late 1930s and became increasingly popular from the 1950s in social science, owing particularly to the use of focus groups in marketing studies in Scandinavia (for a synthesis, see Wilkinson, 1998; Wilkinson \& Kitzinger, 1996). Our focus group interviews aimed to obtain data from a purposively selected group of individuals rather than from a statistically representative sample of a broader population. As Stewart and Shamdasani (1990, p. 102) noted: "The most common purpose of a focus group interview is for an in-depth exploration of a topic about which little is known". Focus groups aim, Kreuger (1994, p. 3) argued, "not to infer but to understand, not to generalize but to determine the range, not to make statements about the population but to provide insights into how people perceived a situation".

In our study, each of the four focus group sessions was video-recorded (Figure 1). Each session was composed of two parts:

- First, participants were asked to express their opinions by using cards about the necessity (or non-necessity) to practice sports at school, and whether they think that it is important that hemophiliacs practice sports at school. Card sorting is a method traditionally used to help design or evaluate the information architecture of a website. In a card-sorting session, participants organize topics into categories that make sense to them, and they may also help us label these groups.

- Second, participants were asked to discuss contents from different websites related to relationships between hemophilia and physical activity. There was always the same moderator for each of the four focus group sessions.

In each of the four groups (Table 1), each participant (children, parents, and teachers) was asked to complete a Likert-scale questionnaire twice: During the first focus group (pre-test; September 2018) and the last focus group (post-test; January 2019). The procedure and questionnaire used in the study are described in the following section.

\section{Procedure and Questionnaire}

During the first and last sessions of a focus group (September 2018 and January 2019), all participants were asked to give their opinion about two questions: (a) "In your view, is it important to practice sports at school?" (Yes vs. No); and (b) "In your view, is it important that hemophiliacs practice sports at school?" (Yes vs. No).

Then, each participant was asked individually to assess eight photos related to different physical activities. Using a Likert scale, for each of these eight photos chosen for our study, all participant were asked to indicate their opinion from 1 ("not dangerous for hemophiliacs") to 7 ("very dangerous for hemophiliacs"). Photos were counterbalanced (i.e., the order of presentation is different) between the two sessions (pre- and post-test).

The questionnaire used in our study concerning physical activity and sports at school was specifically created to investigate opinions of individuals about different sports and physical activities. For each of eight photos representing sports (Figure 1), each participant was asked to indicate his/her opinion from 1 ("not dangerous for hemophiliacs") to 7 ("very dangerous for hemophiliacs"). 




Badminton

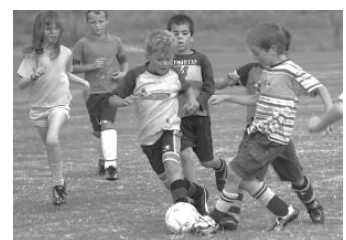

Soccer

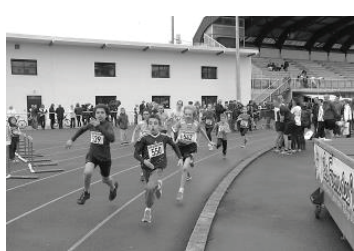

Running

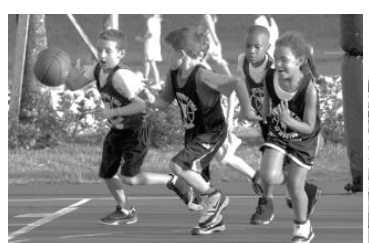

Basketball

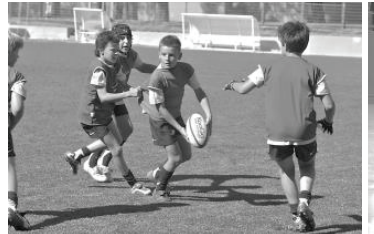

Rugby

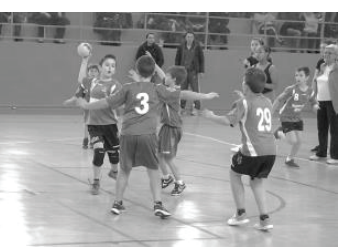

Volleyball

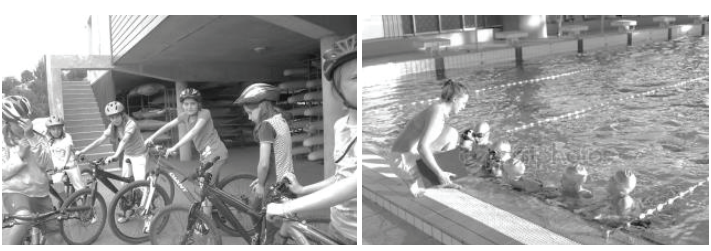

Cycling

Swimming

Figure 1. Photos used in the study showing physical activities and sports

\section{Results}

First, during the pre-test at the beginning of the study (September 2018), for the question "In your view, is it important to practice sports at school?", $100 \%$ of the participants responded "Yes". But, in the same period (pre-test), the distribution of responses was very different for the question, "In your view, is it important that hemophiliac practice sports at school?" As Table 2 shows, while $100 \%$ of the children responded "Yes", only 10 fathers (62.5\%), 8 mothers (50\%), and 7 teachers (43.8\%) responded "Yes" to this question.

Table 2

Sports is important for hemophiliacs: Responses "Yes" given by the participants during the pre-test and post-test

\begin{tabular}{lccccc}
\hline \multirow{2}{*}{ Participant } & & $\begin{array}{c}\text { Sports is important for hemophiliacs } \\
\text { Pre-test }\end{array}$ & Post-test & Chi square & p \\
\hline \multirow{3}{*}{ Child } & Yes & 16 & 16 & $/$ & $/$ \\
& $\%$ & $100 \%$ & 100 & & \\
\multirow{3}{*}{ Father } & Yes & 10 & 14 & 6.48 & .06 \\
& $\%$ & $62.5 \%$ & 87.5 & & \\
\multirow{2}{*}{ Mother } & Yes & 8 & 14 & 11,6 & .003 \\
& $\%$ & $50 \%$ & $10 \%$ & & \\
\multirow{2}{*}{ Teacher } & Yes & 7 & 12 & 13,2 & .002 \\
& $\%$ & $43.8 \%$ & $75 \%$ & & \\
\hline \multirow{2}{*}{ Total } & Yes & 41 & 53 & 10,7 & .005 \\
& $\%$ & $64.1 \%$ & $82.8 \%$ & & \\
\hline
\end{tabular}




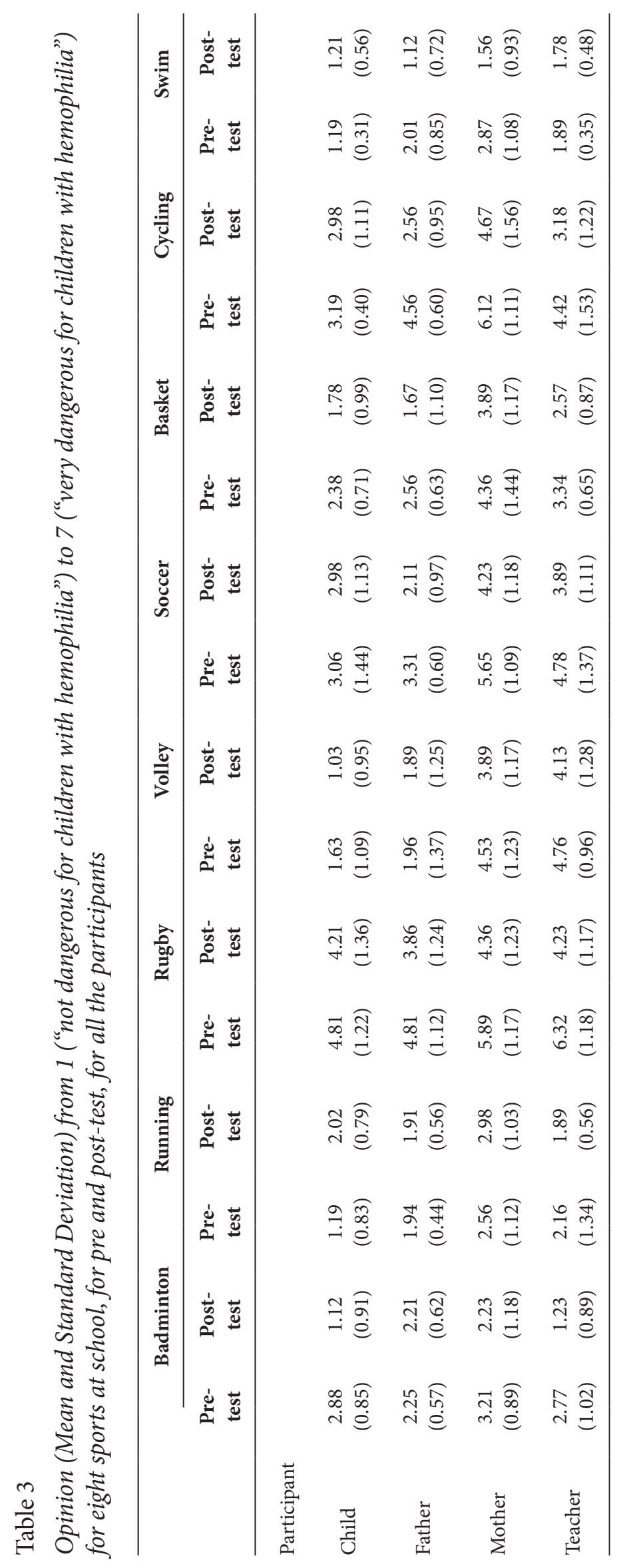


Second, during the post-test, the responses of the participants were very different: As shown in Table 2, the number of respondents who answered "Yes" to the question "In your view, is it important that hemophiliacs practice sports at school?" has increased significantly. While the increase in fathers saying that sports is important for hemophiliacs is not statistically significant $(p=.06)$, the increase is, however, statistically significant for mothers $(p=.003)$ and for teachers $(p=.002)$.

Third, as Table 3 shows, opinions about the different physical activities and sports are different among the groups. Multivariate analysis of covariance (MANCOVA) showed that mothers have more negative opinions about sports than children do $(\mathrm{F}(3-61)=4.61, p<001)$, the difference between the opinions of mothers and fathers being not significant $(\mathrm{F}(3-61)=1.18, p=.34)$. Moreover, fathers and mothers have more negative opinions about sports than teachers (respectively, $\mathrm{F}(3-61)=4.03, p<001$ and $\mathrm{F}(3-61)=3.65, p<001)$.

Four, fathers, mothers, and teachers perceive three sports as more risky than others: rugby, soccer, and cycling. These three sports particularly involve physical contact with others, possible collisions, and the risk of falling. The two sports viewed as the least risky are swimming and running, because physical contact with others is limited and the environment (e.g., water for swimming) is perceived as less dangerous. But whatever the sport, data obtained in the post-test show that opinions become more positive for all the participants, even if the difference is only statistically significant for soccer $(\mathrm{F}(3-61)=5.42, p<.001)$ and cycling $(\mathrm{F}(3-61)=3.67$, $p<.001)$. In other words, fathers, mothers, and teachers modified their opinions positively about the importance and necessity of physical activity and sports at school for children with hemophilia.

Five, one of the main results obtained is to show that in order to design, develop and deploy effective tools for learning (here, a serious game), it is necessary to consider all the stakeholders (here, children, parents, teachers, educators, and researchers). All the participants of our focus groups agreed to create different minigames in the serious game, each minigame being focused on three specific domain related to haemophilia: (i) some basic background about haemophilia; (ii) treatments to improve quality of life for patients; (iii) physical activities with a high and a less risk for injury. In each minigame, the players had to answer questions correctly if they landed on certain spaces to win "Factor cards" (a metaphor for clotting "Factor" in the blood of hemophiliacs) that they could keep and use later to get ahead or protect them from slipping backwards in the game. As many studies based on serious game show, players learn more about the disease through the game (i.e., with a gameplay), which motivates them in an interactive practice. Moreover, five general design factors were formulated based on the analysis of our focus group data: (1) anonymity, which has implications for the use of the future serious game, (2) interactivity, as it facilitates engagement and ensures better uptake of interventions; (3) portability of the technologies, as it ensures privacy and effortless use; (4) source of the information within the application has to be visible and reliable to be perceived as trustworthy and (5) comprehensibility, meaning more visually aided and easily worded information. 


\section{Discussion}

At the end of all five sessions of the focus group interviews (January 2019), an architecture for the educational game had been produced. A prototype will be developed for testing for 2020. The prototype, based on verbalizations collected during all the four focus groups sessions, will be organized with several distinct parts:

- A general part for parents, teachers and children with contents about "What is haemophilia?" and "General principles of care";

- A specific part about "Fitness and physical activity for haemophiliacs": this second part will be specifically concerned with the serious game. The serious game will provide several activities such as "detection of hazards". In this case, different sports and physical activities will be proposed on images and gamers (e.g., teachers, parents of children) must detect potential hazards in the situation. Some sports will be non-contact sports such as swimming, walking, golf, badminton, archery, cycling, rowing, sailing, and table tennis while other sports will be high contact and collision sports such as soccer, hockey, rugby, boxing, and wrestling, as well as high-velocity activities such as motocross racing and skiing. For each of the situation described in pictures, participants (e.g., teachers, parents or children) will be invited to click by using the mouse (with the PC version) or their fingers (with the tactile tablet version) on the physical of social elements that represent potential hazards in the images. A score (i.e., the number of right responses) and the time response (in seconds) will be computed.

The collaborative design of this prototype of an innovative educational tool was also a way to positively influence opinions about physical activity and sports at school for children with hemophilia, and the present paper has concentrated on opinions of individuals (children, fathers, mothers, and teachers) at the beginning and end of the process of collaborative design.

The ultimate goal of our work is to empower children affected by hemophilia and other bleeding disorders to manage their circumstances and challenges autonomously. Because inactivity and overprotection often bring with them issues such as isolation due to poor social interaction and weight problems due to lack of exercise, helping children with hemophilia in this respect is important. Our study shows that to integrate children, their parents, and their teachers in a participatory co-design process for an educational game related to hemophilia can have a significant and positive impact on their opinions. One of our main objectives was to assert that a child with hemophilia is a normal child who happens to have a bleeding disorder.

\section{Conclusion}

Physical activity and exercise have many positive benefits for health and can improve self-esteem, learning, and inclusion in schools, and even if such activity holds particular risks for children with hemophilia, there are also particular benefits for them, such as strong muscles, good balance, and good posture, which in turn help protect the joints from bleeding. In the same way, maintaining a healthy weight 
will reduce stress on joints that have already been damaged by bleeding. Physical activity is almost as important from a psychological point of view, because it has positive benefits with respect to inclusion, self-esteem, and social relationships between peers.

Parents and teachers may have some apprehensions as the school years begin. Psychosocial support is an important part of comprehensive care for people dealing with hemophilia (children, parents, teachers). Beyond the medical condition, individuals with hemophilia commonly face a number of psychosocial challenges. School psychologists play a key role in helping new patients and their families adapt and learn to cope with their new reality.

Although the choice of physical activities or sports must be individually assessed and discussed with psychologists, parents, teachers, and the children themselves, the risks and benefits of different sports should be taken into account. Finally, because the main objective of this work is to influence the mental representation of parents and teachers regarding the importance of physical activity and sports at school for hemophiliacs, we are convinced that the inclusion of children, their parents, and their teachers in a participatory co-design process of an innovative digital tool about hemophilia would be beneficial. In future investigations, the acceptability and the impact of its use should be evaluated.

\section{Limitations}

Two main limitations prevent us from generalizing the results obtained. First, because our study is based on a single post-test performed at the end of the process of collaborative design, further investigation is needed to evaluate its impact over time (e.g., six months later). Second, further investigation should consider the medical history of each family, such as previous bleeding episodes. Such episodes can influence the opinions and attitudes of fathers and mothers of a child with hemophilia.

\section{Acknowledgements}

This research was supported by La Fondation Maladies Rares (the Philomene project)

\section{References}

Bate, P., \& Robert, G. (2006). Experience-based design: From redesigning the system around the patient to co-designing services with the patient. Quality and Safety in Healthcare, 15, 307-310. https://doi.org/10.1136/qshc.2005.016527

Bate P., \& Robert G. (2007) Toward more user-centric OD: Lessons from the field of experience-based design and a case study. Journal of Applied Behavioral Science 43, 41-66. https://doi.org/10.1177/0021886306297014

Beltrand, J., Godot, C., Kerbouch, S., Lepage, N., Jourdon, I., Polak, M., \& Schmidt, M.E. (2017). Utilisation d'un serious game dans l'éducation thérapeutique des patients d'âges pédiatriques atteints de diabète de type 1 : évaluation de l'intérêt et de l'adhérence chez des patients âgés de 10 à 16 ans. Annales d'Endocrinologie, 78(4), 203-204. https://doi.org/10.1016/j.ando.2017.07.749

Boyd, H., McKernon, S., Mullin B., \& Old, A. (2012). Improving healthcare through the use of codesign. The New Zealand Medical Journal, 125, 76-86. 
Bowen, S., Dearden, A., Wolstenholme, D., \& Cobb, M. (2011). Different views: Including others in participatory health service innovation. In J. Buur (Ed.), PINC 2011: Participatory innovation conference, Sonderborg, Denmark, 29 November-3 December 2010. Retrieved from http://shura.shu.ac.uk/3536/ (accessed 30 April 2019).

Chomutare, T., Johansen, S.G., Hartvigsen, G., \& Arsand, E. (2016). Serious game co-design for children with type 1 diabetes. Studies in Health Technology and Informatics, 226, 83-86.

Colegrove, R., \& Huntzinger, R. (1994). Academic, behavioral, and social adaptation of boys with hemophilia/HIV disease. Journal of Pediatric Psychology, 19(4), 457-473. https://doi.org/10.1093/jpepsy/19.4.457

Dinet, J. (2015. Effet de l'hémophilie sur la perception des risques liés aux activités de plein air à lâge scolaire. Enfance, 2, 199-223. https://doi.org/10.4074/S0013754515002037

Fromme, A., Dreeskamp, K., Pollmann, H., Thorwesten, L., Mooren, F.C., \& Volker, K. (2007). Participation in sports and physical activity of haemophilia patients. Haemophilia, 13(3), 323-327. https://doi.org/10.1111/j.1365-2516.2007.01456.x

Godot, C., Maccini, P., Lepage, N., Jourdon, I., Gonzalez, L., Stupa, A., ... Beltrand, J. (2016). CA-211: DIVE : Le premier Serious Game pour léducation thérapeutique de l'enfant et de l'adolescent atteint de diabète de type 1. Diabetes \& Metabolism, 42(1), a93. https://doi.org/10.1016/S1262-3636(16)30343-3

Gomis, M., Querol, F., Gallach, J.E., Gonzalez, L.M., \& Aznar, J.A. (2009). Exercise and sport in the treatment of haemophiliac patients: a systematic review. Haemophilia, 15(1), 43-54. https://doi.org/10.1111/j.1365-2516.2008.01867.x

Gregory, M., Boddington, P., Dimond, R., Atkinson, P., Clarke, A., \& Collins, P.W. (2007). Communicating about haemophilia within the family: The importance of context and of experience. Haemophilia: The Official Journal of the World Federation of Haemophilia, 13(2), 189-198. https://doi.org/10.1111/j.1365-2516.2006.01417.x

Gustavsson, S.M., \& Andersson, T. (2017). Patient involvement 2.0: Experience-based co-design supported by action research. Action Research. https://doi.org/10.1177/1476750317723965

Gustavsson, S. (2014). Improvements in neonatal care; using experience-based codesign. International Journal of Health Care Quality Assurance, 27, 427-438. https://doi.org/10.1108/IJHCQA-02-2013-0016

Heijnen, L., Mauser-Bunschoten, E.P., \& Roosendaal, G. (2000). Participation in sports by Dutch persons with haemophilia. Haemophilia, 6(5), 537-546. https://doi.org/10.1046/j.1365-2516.2000.00422.x

Iedema, R., Merrick, E., Piper, D., Britton, K., Gray, J., ... Manning, N. (2010). Co-designing as a discursive practice in emergency health services: The architecture of deliberation. Journal of Behavioral Science, 46, 1-19. https://doi.org/10.1177/0021886309357544

Joubert, M., Armand, C., Morera, J., Tokayeva, L., Guillaume, A., \& Reznik, Y. (2016). Impact of a serious videogame designed for flexible insulin therapy on the knowledge and behaviors of children with type 1 diabetes: The LUDIDIAB Pilot Study. Diabetes Technology and Therapeutics, 18(2), 52-58. https://doi.org/10.1089/dia.2015.0227

Jurdi, S., Montaner, J., Garcia-Sanjuan, F., Jaen, J., \& Nacher, V. (2018). A systematic review of game technologies for pediatric patients. Computers in Biology and Medicine, 97, 89-112. https://doi. org/10.1016/j.compbiomed.2018.04.019

Krueger, R. A. (1994). Focus groups: A practical guide for applied research. London: Sage.

Larkin, M., Boden, Z., \& Newton, E. (2015). On the brink of genuinely collaborative care: Experience based co-design in mental health. Qualitative Health Research, 25, 1463-1476. https://doi.org/10.1177/1049732315576494

Manco-Johnson, M.J. (2012). Collision sports and risk of bleeding in children with hemophilia. JAMA, 308(14), 1480-1481. https://doi.org/10.1001/jama.2012.13303

Maher L., Baxter H. (2009). Working in partnership with service users. Service Design, 15, 172-175. https://doi.org/10.12968/bjhc.2009.15.4.41719

Matsunaga, R.M., Moraes, R.L., Borges, M.A., Matta, M.A., \& Ozelo, M.C. (2014). Development of a serious game for children with hemophilia. 2014 IEEE 3nd International Conference on Serious Games and Applications for Health (SeGAH), 1-6. https://doi.org/10.1109/SeGAH.2014.7067082 
Pickles, J., Hide, E., \& Maher, L. (2008). Experience-based design: A practical method of working with patients to redesign services. Clinical Governance: An International Journal, 13, 51-58. https://doi.org/10.1108/14777270810850634

Ross, C.N., Goldenberg, N.A., Hund, D., \& Manco-Johnson, M.J. (2009). Athletic participation in severe hemophilia: Bleeding and joint outcomes in children on prophylaxis. Pediatrics, 124(5), 1267-1272. https://doi.org/10.1542/peds.2009-0072

Sanders, E.B.-N. (2006). Nurse and patient participatory workshops for the NBBJ project. Inpatient tower expansion for H. Lee Moffitt Cancer Center and Research Institute, Tampa, FL, USA.

Sanders, E.B.-N. \& Stappers, P.J. (2008) Co-creation and the new landscapes of design. CoDesign, 4(1), 5-18. https://doi.org/10.1080/15710880701875068

Shapiro, A.D., Donfield, S.M., Lynn, H.S., Cool, V.A., Stehbens, J.A., Hunsberger, S.D., .. Gomperts, E. (2001). Defining the impact of hemophilia: The Academic Achievement in Children with Hemophilia Study. Pediatrics, 108(6), E105. https://doi.org/10.1542/peds.108.6.e105

Stewart, D.W. \& Shamdasani, P.N. (1990). Focus groups: Theory and practice. Newbury Park, CA: Sage.

Tsianakas, V., Robert, G., Maben, J., Richardson, A., Dale C., \& Wiseman, T. (2012). Implementing patient-centered cancer care: Using experience-based co-design to improve patient experience in breast and lung cancer services. Support Care Cancer, 20, 2639-2647. https://doi.org/10.1007/s00520-012-1470-3

Usner, D., Donfield, S.M., Sirois, P.A., Gomperts, E., Bale, J.F., \& Mitchell, W.G. (1998). Hemophilia morbidity, cognitive functioning, and academic achievement. The Journal of Pediatrics, 133(6), 782-787. https://doi.org/10.1016/S0022-3476(98)70151-9

Van der Net, J., Vos, R.C., Engelbert, R.H., van den Berg, M.H., Helders, P.J., \& Takken, T. (2006). Physical fitness, functional ability and quality of life in children with severe haemophilia: A pilot study. Haemophilia, 12(5), 494-499. https://doi.org/10.1111/j.1365-2516.2006.01307.x

Von Mackensen, S. (2007). Quality of life and sports activities in patients with haemophilia. Haemophilia, 13(2), 38-43. https://doi.org/10.1111/j.1365-2516.2007.01505.x

Williams, K.A. \& Chapman, M.V. (2009). Social challenges for children with hemophilia: Child and parent perspectives. Social Work in Health Care, 50(3), 199214. https://doi.org/10.1080/00981389.2010.527790

Wilkinson, S. (1998). Focus group methodology: a review. International Journal of Social Research Methodology. Theory and Practice, 1(3), 181-204. https://doi.org/10.1080/13645579.1998.10846874

Wilkinson, S. \& Kitzinger, C. (1996). Representing the other. London: Sage.

Original manuscript received August 23, 2019

Revised manuscript accepted October 20, 2019

First published online December 25, 2019

To cite this article: Dinet, J., Bauchet, C., Hoareau, L. (2019). Collaborative Game Design with Children with Hemophilia as a Tool for Influencing Opinions about Physical Activity at School. Psychology in Russia: State of the Art, 12(4), 159-171. DOI: 10.11621/pir.2019.0410 